\title{
Women's Participation in Governance and Political Processes in Kenya: Threats and Proposed Remedies
}

\author{
Dr. Geoffrey Korir \\ Communication, Media \& Social Media Strategist, Blif Tech Startup, San Francisco, United States
}

Dr. Hellen Amunga

Department of Library \& Information Sciences, University of Nairobi, Kenya

\begin{abstract}
Most recent studies on women's political participation demonstrate that women are consistently denied adequate space and a level playing field to participate in politics and governance, especially in many global south countries, unlike their male counterparts. These studies' most dominant claim is that these contexts' patriarchal cultural norms mainly limit women's central involvement in such nations' political processes. Based on this impediment system, it follows that these environments become more unpropitious, hostile, and insecure for women in politics, which opens up and perpetuates possibilities for all manner of harm to them. Because of such threats, several scholars, religious leaders, and women activists decry the underrepresentation of women in politics, which in their understanding, has contributed to prolonged systemic discrimination through a legacy of insufficient woman-centric legislation and policy interventions. There is a consensus-based claim among the majority of these actors that this kind of inadequacy continues unabated due to a siloed thinking that inhibits a joined-up approach in tackling such discrimination. This paper seeks to further explore this claim through a broad stroke integrated review of literature that deals with women's political participation in Kenya, where the concept of traditional gender role beliefs provides a vital backdrop for conducting it. Based on this concept's valuable terms of reference, it is concluded that women need to be accorded a more enabling environment to participate in politics and, in this way, ensure that their ascension to leadership positions in governance becomes tenable. It is anticipated that such an assumption will increase legislation, policy and other interventions geared towards safeguarding women's general participation in politics. In light of such conclusion, it is proposed that groundswell support is needed to ensure that the creation of a conducive environment for women to be involved in politics is realized, and in this way, their disenfranchisement based on their limited participation in politics is tackled.
\end{abstract}

Key words: Women Disenfranchisement; Women \& Governance; Affirmative Legislation; Politics \& Traditional Gender Role

\section{INTRODUCTION}

Critical forms of reflexive thinking developed from interpretative approaches to gender studies signify that a leadership framework predicated on the inclusionary instantiation of women is the boon for which any nation's successful governance does not remain illusory. A cacophony of competing voices posits causal relationships between the absence of a gulf in an eclectic mix of ideas that would have otherwise not been garnered through the exclusion of women in such framework and the underpinning of such nation's presence of efficaciousness in governance. In this vein, it is often propounded that this inclusion is not an anathema to this governance's effectiveness as a section of the citizenry discerns, in a rationalist fashion, how much government is not far removed from the centre in terms of its responsiveness to their needs. An observable pattern of philosophical fallibilism emerges in this context that this realization is derivable from deterministic causes through the existence of sufficient policy and legal frameworks that are designed to respond to their needs in toto. A broad body of data gathered through in-depth interviews and quantitative surveys demonstrate that many such governments are found in several global northern countries, explicitly referred to as success stories. A reductionist approach that surface in this context is that these countries afford traction upon which others can establish and implement a whole gamut necessary for attaining women's inclusivity in their politics and governance.

Within the framework of contending discourses on the broader subject of such crystallization, there is an empiricist claim that most global south countries in general, and African countries in particular, bear the imprints of countries that can use the ones mentioned above as formulaic points of reference for attaining women's inclusivity in their governance structures. Various circumlocutions from a series of recent studies 


\section{Yinternational Research Journa}

p-ISSN 2202-2821 e-ISSN 1839-6518 (Australian ISSN Agency)

indicate that such a claim is presented as a confirmation and verification of overarching deficiencies in women's representation in leadership positions. Pandering to the multiplicity and interactive impacts resulting from these deficiencies, a consilience of inductions emerges regarding how they have brought about many undesirable outcomes in these countries' governance, which is primarily driven by the extreme opposite approach of the holistic approach in solving women's problems. This holistic resonance is derivable from antirealist tradition pertaining to the absence of or insufficient policy and legislation frameworks designed to respond to these problems.

This embodiment affords leverage points and the conceptual traction upon which to establish an argument that many actors in these countries' domains of activism, academia, and religion, more generally, are now reaffirming and obscuring relations of force to counter such structures that do not allow for the diminution of exclusive leadership. Some of their efforts to develop necessary complementary policy prescriptions are essential enrichment to the ongoing conversations in the literature regarding a series of essential reforms necessary for bringing about women's inclusivity in political processes and governance. However, even with such proposals, there is a sense of imminence and foreboding within such conversations about their successful implementation as many global south nations are still not doing enough to dispense with this problem of exclusion today. In this context, Kenya is repeatedly cited as established from the many ongoing discourses on this broader subject of women disenfranchisement in political and governance processes.

This paper is ergo pedestaled on building on extant literature by posing questions and sparking conversations about the place of women in Kenya's political and governance processes. It makes an ineliminable link to the concept of traditional gender role beliefs as a vital backdrop for such conversations. More particularly, this concept provides valuable terms of reference for understanding why the country is still unamenable to women's inclusivity in politics and governance even with the profound recognition of their exclusion. The following section presents posteriori knowledge derived from traditional gender role beliefs' core formulation that provides valuable terms of reference for this paper's analysis of the retrieved secondary data.

\section{The concept of traditional gender role beliefs}

A consensus-based claim that emerges within highly intellectual discourses around a vast range of gender issues is that the general beliefs that reinforce the acceptance of the responsibilities and behaviors for women and men as true are firmly situated within the structuration of fundamentally internalized social and cultural values. Against the backdrop of this often emergent claim, it is propounded within the contours of an 'essentialist framing' that those ascribing to traditional gender role beliefs hold, on the one hand, that a woman's role is limited to that of a home caretaker and on the other hand, a man's role entails providing his family with financial support as its sole breadwinner (Corrigal \& Konrad, 2007; Eagly, 1987; Eccles et al., 1983; Williams \& Best, 1990).

At this juncture, anecdotal evidence suggests in comparative terms that since this framework of thinking has more purchase in men than in women, much more emphasis is ultimately placed on men's careers than on women's (Brewster \& Padavic, 2000; Larsen \& Long, 1988). In the aggregate, it is then argued through the concept of 'aesthetic disposition' that this emphasis distils into how women and men end up constructing their social identities, their anticipated future roles and finally, their short and long-term goals. In other words, this emphasis is deliberately fragmented into key predictors for women's and men's aspirations that end up determining, in a way, the educational and occupational choices they make and pursue (Eccles \& Bryan, 1994; Eccles et al., 1999; Schoon \& Parsons, 2002; Webb et al., 2002).

In the context of these nomothetic generalizations, the conventional narrative review of the literature expounds those women who hold traditional gender role beliefs associated with family and work roles are more likely to focus on family responsibilities. This commitment's interpretive synthesis suggests that it results in consequences for these women's choices regarding their educational and occupational aspirations and their attainment. On the flip side, it follows that a decline in the adherence to traditional work and familyrelated gender role beliefs within society, in general, is almost ubiquitously connected with increases in educational attainment for females (Brooks \& Bolzendabhl, 2004; Buchmann et al., 2008; Goldin, 2006). In this context, it is probably practical that the attainment of education in this sense is concomitant with the fulfilment of women's participation in political processes and governance.

Indeed, it is possible to realize from a variety of paradigmatic perspectives that even though the overt support for traditional gender role beliefs is diminishing today, its core beliefs about women and men's roles in society still provides a valuable backdrop for analyzing causal conditions impeding women's involvement in politics and governance (Bolzendahly \&

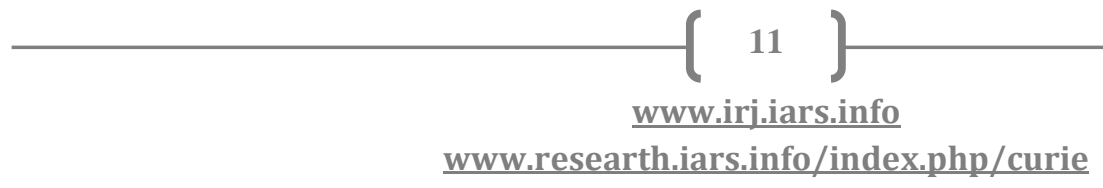




\section{Yinternational Resoarch Journa}

p-ISSN 2202-2821 e-ISSN 1839-6518 (Australian ISSN Agency)

Myers, 2004; Brooks \& Bolzendahly, 2004; Raley et al., 2006). An essential pillar in this analysis framework is the concatenation of gender role beliefs and people's gendered expectations in the successful attainment of various gendertyped occupations (Eccles et al., 1983). In this context, it is possible to argue that traditional gender role beliefs are most likely to drive across gender differences in politics-related occupational attainment in some essential respects.

To this end, one can argue that the concept of the traditional gender role beliefs makes an essential enrichment on a framework of analysis geared towards establishing the inclusionary and exclusionary decisions that contribute to the level of participation of women in Kenya's politics and governance. This concept's core formulation, regarding people's perspectives about women's roles being delegated to housekeeping, helps us understand, in particular, the dialectic factors influencing women's general performance in the country's political processes and governance.

\section{Methodology - A qualitative systematic review research design}

As already established, this paper set out to gain insight into the causal mechanisms for lower levels of women's participation, or absolute lack of it, in political processes and governance in Kenya. Therefore, as the initial step geared towards achieving this paper's aim, the first task included the general retrieval of secondary data on the broader subject of women's involvement in Kenya's politics and governance for review. It was anticipated that the retrieved data would be used as an actual depiction of their involvement as it currently exists in Kenya. It was assumed that the secondary data that would best bring about this reality was those obtained from books and journal articles, evaluative reports commissioned by different stakeholders, unpublished dissertations, papers presented in various conferences and workshops and newspaper and website articles. This assumption was based on the cognizance that those who had participated in gathering these secondary data were some of the key actors briefly referred to in this paper's introduction, mainly academics and activists, who can easily fit into the category of the individuals considered to be well informed about the level of women's participation in politics and governance in Kenya.

Having identified and retrieved the necessary secondary data for analysis, the second task included purposively identifying and selecting the most recent ones as these were the most preferred for analysis. This preference mainly was based on the period the researchers had gathered and presented these data through their various forms of publications, and it was
Vol. 11 No. 022021 828011022021173 (C) Author(s)

anticipated that such should not have been older than two decades by the time of writing this paper. The secondary data collected and presented within this timeframe were selected as they were deemed the most appropriate for analysis.

After settling on these data, the most crucial task of analyzing them by way of integrative review began. We anticipated that the analysis framework that we had already established in the previous discussion would play a fundamental role in providing a valuable backdrop for this task. In more general terms, this framework would offer essential terms of reference for interpreting and understanding the involvement of women in Kenya's politics and governance. More particularly, the articulation of the concept of traditional gender roles beliefs would provide a launching pad or sounding board for analyzing this involvement by deriving dialectic inductions regarding why women's degree of participation is in such a manner. In more particular terms, it would entail bringing into sharp focus both Kenyan men and women's views about the latter's participation in political processes and governance in the country and the degree to which these views contribute to the outcome of this participation.

With some of these useful terms of reference in mind, the main task of reading and rereading the selected secondary data to gain a general understanding of the level of Kenya's women's involvement in various leaderships in government began. As this process progressed, it was possible to extract the main ideas regarding the degree of their involvement as presented in the selected data. It was then decided that these ideas had to be divided into smaller chunks referred to as the meaning units. It was essential to condense these units further. This process was conducted while ensuring that the core meaning was still retained. These condensed meaning units were labelled by way of formulating codes and then grouping them into themes. Once this process was complete, the main task of analyzing and drawing conclusions in response to this study's objective followed (Erlingsson \& Petra, 2017; Luo, 2019).

\section{Women's participation in Kenya's political processes and governance}

The discussion in this section represents this paper's core area as it focuses on the analysis of the retrieved relevant secondary data obtained from the sources mentioned in the previous section. For analytical clarity purposes, this analysis begins by establishing categories of elective political positions in Kenya more generally, followed by actors eligible to contend emulously and eventually have a better prospect of assuming these positions. It then moves to a more detailed 


\section{Yinternational Research Journal}

p-ISSN 2202-2821 e-ISSN 1839-6518 (Australian ISSN Agency)

counterintuitive examination regarding how some of these actors and more particularly women, are impeded from participating in these processes in part and wholly compared to their male counterparts. It after that deals in some essential respects with the most practical foregrounded adjustive approaches invested in mitigating against many of these impediments. Finally, the discussion concludes by establishing how the insights fragmented by the pressures exerted by various debates in the obtained secondary data resonate with the posteriori knowledge derived in this paper's earlier discussion.

At the very outset, it is noticeable from the reviewed secondary data that categories of elective positions in Kenya are well articulated and presented in the country's constitution, electoral body's different modes of documentation including various publications. It is possible to confirm and verify from these documentations that since the promulgation of the Constitution of Kenya 2010, elective posts in Kenya are both at national and county levels; and affirmative action that entrenches women into various political positions is in place. These positions are formally established within the following broad categories; National Executive, Parliament (Senate and National Assembly), County Executive and County Assembly (Githinji, 2021; Kinya, 2017). It is noted in the remits of the above concordance of evidence that these different elective positions require various qualifications that ought to be met by those willing to occupy them. It follows that upon meeting these requirements and being cleared by the electoral body, interested individuals can then officially begin campaigning for those respective positions, an event that culminates with voting and identification of the winner. It is explained in the above body of works that these victors can come from any tribe, religious affiliation, race, and gender - save for the Women Representative position at each of the country's 47 counties, which is reserved for women, This reality can be reaffirmed as accurate given that at the very outset, these works affirm that all qualified candidates, regardless of their different orientations, can vie for any elective seat in Kenya (CMD-Kenya, 2011; Githinji 2021; Kinya, 2017).

Evidence is mounting that even though anyone from these orientations is entitled to contest for any elective position in the country, some are impeded by multiple factors inextricably enmeshed in their demographics. An observable pattern that reprises within civic discourses about such limitation is that those from the marginalized tribes in Kenya and women are the most affected. Within recent discussion of findings in a series of studies regarding this disenfranchisement, most authors agree that women are the most affected in this web of
Vol. 11 No. 022021

828011022021173 (c) Author(s)

signification. In this context, these authors present clear and comprehensive narratives regarding several particularly pronounced themes about the extent of women's participation in politics and significant disruptions obliterating this participation (Anyango et al., 2018).

Although manifold colorations regarding women's lower levels of participation in political processes are complex and open to different interpretations, many accounts in the reviewed evidence and experts' opinions are primarily discerned in the dominant ideology of patriarchal predilection. Here, commentators galvanize a consensus-based claim of how this bias has confined women to the peripheries of leadership in Kenya as the society in general views all activity women engage in from a man's general outlook. Therefore, in this case, a woman who ventures into a political contest is more likely to receive a backlash or, in the worst-case scenario, assaulted physically. This statement retains openness to further interpretations through intelligentsia's argument regarding how married women are the most disadvantaged in such a manner. It is argued in this context that many married women interested in vying for political positions are forced to choose between their families and leadership due to the coercive nature of their husbands, who hold that women ought not to run for these positions in the first place (Boulanger, 2008; Mbarika et al., 2007; Morojole, 2011; Musandu, 2008; Owuor, 2016; Ringera, 2017).

It is probably most practical that lack of this sufficient support begets insufficient capital that women require to participate in electoral processes. In operating from a comparative framework, it is argued that unlike their male counterparts, many women who are interested in political seats are precluded from accessing the same sources of funding as they find themselves bereft of overt financial support from influential individuals within the established systems of authority and in business. Holistic perspectives of participants in the retrieved data suggest that this inadequacy is arguably a problem aggravated by few women in spheres where such deals are hatched (Biegon, 2016; Black \& Erickson, 2003; Ringera, 2017). On this conception, women's limited presence in such spaces is contingent on various forms of harm that may come upon them. Based on this possibility, the reviewed evidence strongly suggests that it is a reality given that in the past, there is evidence of men ganging up against women running for the same seats as them by meting violence to intimidate them. Within discussions of this nature, the literature points out that women facing formidable opposition from influential male candidates have had to seek government

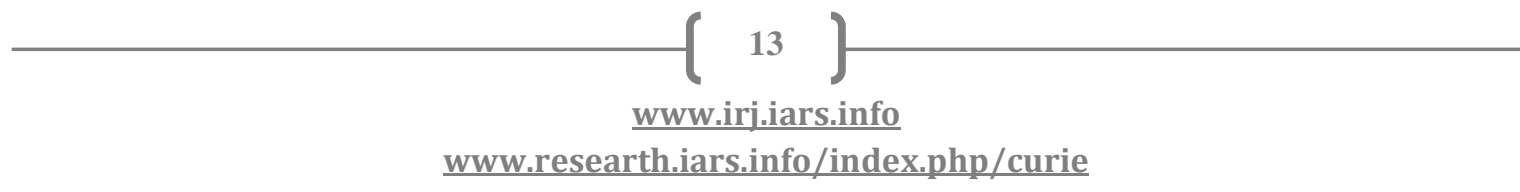




\section{Yinternational Research Journal}

p-ISSN 2202-2821 e-ISSN 1839-6518 (Australian ISSN Agency)

protection in subsequent elections because of incessant threats (Anyango et al., 2018; Ringera, 2017).

Antithetical to the above challenges, some authors apply a reductionist approach by propounding in relative terms that some women do not support other women vying for political office because of internalization that men are well equipped than women to occupy political positions. Incontrovertible evidence demonstrates this reality by indicating that even though women constitute the majority in Kenya's population, there are a few women elected to public office today. Contemporary notions of evidence-based practice qualify this statement by citing an example in 2007 where in Meru County, out of the 15 aspirants who vied for a parliamentary seat in one of its constituencies, only one was a woman. The case was no different in the 2013 election where no woman nationwide, for example, vied for the position of a governor. In the subsequent election in 2017, about 20 women vied either for governor or deputy governor positions nationally. This number was still minimal compared to male aspirants (Lichuma, 2017; Ringera, 2017).

Built upon the premise of the above problem of few women engaging in subsequent electoral processes in Kenya, the reviewed secondary data proffers an observable pattern reminiscent of the concept of 'liberating pedagogy' through different actors' concerns, including activists and academics more particularly. Based on reflections of these concerns, other challenges facing the country and a more resonant quest to address them, a new dispensation came with the promulgation of the Constitution of Kenya in 2010 as an intervention. Indeed, this dispensation is hailed in ongoing conversations in literature as a defining moment in the country's history, given that the new constitutional framework formed a pedestal for the emancipation and liberation of women through a provision that neither gender should occupy more than two-thirds of any public governance seats in addition to reservation of the County Woman Representative position. In other words, these provisions created and secured many opportunities for women in the form of elective, nominative, and appointive positions (CREAW, 2017; Lichuma, 2017; Ringera, 2017).

Among the most lucid thinking that emerges in the context of such provisions is that a lot still needs to be accomplished to make women's inclusion in elective political processes and governance a great success. This need is particularly pronounced given the repeated exposure of women's continued exclusion even after the promulgated Constitution of Kenya 2010 had provided for an emancipatory promise by creating a gender-friendly legal framework that would enable women to participate across Kenya's governance structures. In this sense, some authors caution against not confronting this persistent problem impeding women from participating in critical decision-making processes touching on people's welfare more generally, and particular concerns of women more specifically. Within their commentaries, they argue how essential it is for this problem to be resolved given that several women have a more significant potential of addressing pertinent governance issues because of their varied talents, such as fostering good relationships and spurring open dialogues (CMD-Kenya, 2011; Lichuma, 2017; Ringera, 2017).

It is possible to identify in varied and multiple empirical facts obtained from credible studies the interrelated levels of decisions that attenuate women's exclusion. In this context, there is an endogenous need for conducting voter's education at all levels, but most notably at the grassroots. The purpose is to enlighten the electorate about the need of overlooking patriarchal norms in electing a leader as such norms may come in the way of electing great leaders based on the gender gap. Based on this persuasion, retrieved findings embed it with additional valuable examples regarding how some democratically elected women leaders perform exceptionally well serving those who elected them. An example often cited by researchers is the setting up maternal health care facilities by influential women leaders in the remote places of the country where women had previously lacked access to such facilities (Kabeer, 2015; Musandu, 2008; Ringera, 2017; Sifuna, 2006).

In the context of the atomization of women leaders' capabilities into such examples, several studies strongly suggest that some Kenyan citizens are becoming more attuned to and aware of women's capabilities in governance and are, for this reason, rising from traditional beliefs that women are undeserving of leadership. Based on this observation, these studies point out that the country's political terrain is now experiencing more vibrant political campaigns from women aspirants leading to a significant increase in the number of women candidates winning various elective seats. It is understood from the reviewed empirical evidence that this progress is occurring whilst some of the previously mentioned challenges for women, such as insufficient funds for campaigns, are still unresolved (Anyango et al., 2018; Milligan, 2014; Odhiambo, 2011). Therefore, although some of these problems are still being felt today, there is hope that gender equality in politics and governance can still be achieved in Kenya. 
In this discussion, we have encountered the degree to which Kenyan women participate in this country's political processes and are included in its governance structures. By the very nature of the extent of this inclusivity, we have seen some of the factors that largely contribute to their exclusion. It has been demonstrated that one of these factors is primarily driven by patriarchal norms, which was well articulated in the previous section's discussion about the concept of traditional gender role beliefs. Another foregrounded factor, as was established here, was the various forms of harm that could occur, or in some cases, had already occurred to women during their campaigns. The following section presents proposals based on such impediments.

\section{Conclusion and Recommendations}

The review of the retrieved secondary data in Section Four suggests that the degree of women's participation in political activities in Kenya is unsatisfactory, and this reality can be confirmed in the number of women holding elective positions today. It was demonstrated that indeed, fewer women are occupying these offices, and this record was attributable on the one hand to some women and men's internalized values system that are deeply entrenched in the concept of traditional gender role beliefs and, on the other hand, various forms of harm that women are potentially subjected to in their political pursuits. However, despite these challenges, it also emerged within the reviewed literature that slight progress in terms of women's inclusivity in political activities and governance had been realized more so because of the new constitution's provision on gender equality. Even though this provision is now in place, we saw that its full implementation is proving rather difficult or transient, as fewer women than men are still occupying elective seats. In this regard, it would probably be fair to say that the problem of women underrepresentation persists.

Considering the above, it can be concluded that the future of women's expected participation in political processes and governance cannot be guaranteed with such challenges unaddressed. Instead, it is the commitment of actors that have been subtly mentioned in this discussion, such as activists, academics, and religious leaders, who will ensure that gender equality is successfully achieved in governance structures. To ensure this success is attained, it will be valuable for these actors to take it upon themselves to educate the general public on the qualities to look for in electing great leaders. As part of doing this, attention should be paid to discouraging them from evaluating political candidates based on traditional gender role beliefs, tribal and political affiliations as opposed to ideology and leadership qualities across the genders. Such effort should be complimented by more effort from the Kenyan government in creating an enabling environment for women to participate in elections. Fully implementing the gender provisions in the Constitution of Kenya 2010 will go a long way in achieving this. Additionally, it is proposed that the government should always enhance the security of women politicians and political aspirants but more specifically during the electioneering period.

\section{References}

[1]. Anyango, B. O., Alupo, B. A., \& Opoku, M. P. (2018). Women in Politics in Kenya: An Analysis of Participation and Barriers. Multidisciplinary Journal of Gender Studies, 7(1), 1505-1530. doi: 10.17583/generos.2018.3179

[2]. Biegon, J. (2016). Gender and Political Processes in Kenya. Strathmore University.

[3]. Black, J. H., \&. Erickson, L. (2003). Women Candidates and Voter Bias. Do Women Politicians Need To Be Better? Electoral Studies. Kenyan Publishers.

[4]. Bolzendahl, C. I., \&. Myers, D. J. (2004). Feminist attitudes and support for gender equality: opinion change in women and men, 1974-1998. Soc. Forces 83, 759-789. doi: 10.1353/sof.2005.0005

[5]. Boulanger, S. (2008). A Puppet on a String: The Manipulation and Nationalization of the Female Body in the" Female Circumcision Crisis" of Colonial Kenya. Wagadu: a Journal of Transnational Women's and Gender Studies, 6, 59. http://sites.cortland.edu

[6]. Brewster, K. L., \&. Padavic, I. (2000). Change in gender-ideology, 1977-1996: the contributions of intracohort change and population turnover. J. Marriage Fam. 62, 477-487. doi: 10.1111/j.17413737.2000.00477.x

[7]. Brooks, C., \&. Bolzendahl, C. (2004). The transformation of US gender role attitudes: cohort replacement, social-structural change, and ideological learning. Soc. Sci. Res. 33, 106-133. doi: 10.1016/S0049-089X(03)00041-3

[8]. Buchmann, C., DiPrete, T. A., \&. McDaniel, A. (2008). Gender inequalities in education. Ann. Rev. Sociol. 34, 319-337. doi: 10.1146/annurev.soc.34.040507.134719

[9]. CMD-Kenya. (2011). Elective, Nominative \& Appointive Positions Unpacked:A Handbook for Women Seeking Leadership Positions. CMDKENYA. 
[10]. Corrigall, E. A., \&. Konrad, A. M. (2007). Gender role attitudes and careers: a longitudinal study. Sex Roles 56, 847-855. doi: 10.1007/s11199-007-9242-0

[11]. CREAW. (2017). Two Thirds Gender Rule Archives. CREAWKENYA.

https://home.creaw.org/category/women-leadershipand-governance/two-thirds-gender-rule/

[12]. Eagly, A. H. (1987). Sex Differences in Social Behavior: A social-role interpretation. Lawrence Erlbaum.

[13]. Eccles, J. S., Adler, T. F., Futterman, R., Goff, S. B., Kaczala, C. M., \&. Meece, J. L. (1983). Expectancies, values, and academic behaviors. In $\mathrm{J}$. T. Spence, Achievement and Achievement Motivation (pp. 75-146). W. H. Freeman.

[14]. Eccles, J. S., \&. Bryan, J. (1994). Adolescence: critical crossroad in the path of gender-role development. In M. R. Stevenson, Gender Roles Through the Life Span, ed (pp. 110-147). Ball State University Press.

[15]. Eccles, J. S., Barber, B., \&. Jozefowicz, D. (1999). Linking gender to educational, occupational, and recreational choices: applying the Eccles et al. model of achievement-related choices. In J. H. W. B. Swann, Sexism and Stereotypes in Modern Society: The Gender Science of Janet Taylor Spence, eds (pp. 153-192). American Psychological Association.

[16]. Erlingsson, C., \&. Petra, E. (2017). A hands-on guide to doing content analysis. African Journal of Emergency Medicine, 7 (3), 93-99. https://pubmed.ncbi.nlm.nih.gov/30456117/

[17]. Githinji, P. (2021). The Six Types of Elective Positions in Kenya. AfroCave.

[18]. Goldin, C. (2006). The quiet revolution that transformed women's employment, education, and family. Am. Econ. Rev. 96, 1-21. doi: $10.1257 / 000282806777212350$

[19]. Kabeer, N. (2015). Gender, poverty, and inequality: a brief history of feminist contributions in the field of international development. Gender \& Development, 23(2), 189-205.https://www.tandfonline.com

[20]. Kinya, E. (2017). Electoral Process in Kenya. KENYA LAW Where Legal Information is Public Knowledge. http://kenyalaw.org

[21]. Larsen, K. S., \&. Long, E. (1988). Attitudes toward sex-roles: traditional or egalitarian? Sex Roles 19, 112. doi: 10.1007/BF00292459
[22]. Lichuma, W. (2017). Gender Equality Challenges in Kenya and Africa. Australian Federal Police at the Australian High Commission in LONDON Offices .

[23]. Luo, A. (2019). What is content analysis and how can you use it in your research? Scribbr. https://www.scribbr.com/methodology/contentanalysis/

[24]. Mbarika, V. W., Payton, F. C., Kvasny, L., \&. Amadi, A. (2007). IT education and workforce participation: A new era for women in Kenya? The Information Society, 23(1), 1-18. https:tandfonline.com

[25]. Milligan, L. (2014). They are not serious like the boys': gender norms and contradictions for girls in rural Kenya. Gender and Education, 26(5), 465-476. https://tandfonline.com

[26]. Morojele, P. (2011). What does it mean to be a boy? Implications for girls' and boys' schooling experiences in Lesotho rural schools. Gender and Education, 23(6), 677-693. https://tandfonline.com

[27]. Musandu, P. (2008). Drawing from the Wells of Culture: Grace Onyango and the Kenyan Political Scene (1964-1983). Wagadu: a Journal of Transnational Women's and Gender Studies, 6, 25. https://www.semanticscholar.org

[28]. Odhiambo, G. (2011). Women and higher education leadership in Kenya: a critical analysis. Journal of Higher Education Policy and Management, 33(6), 667-678. https://tandfonline.com

[29]. Owuor, E. (2016). Women and political inclusion in Kenya: A historical overview, 1963-2016. In J. Biegon, Gender and Political Processes in Kenya (pp. 7-38). Strathmore University.

[30]. Raley, S. B., Mattingly, M. J., \&. Bianchi, S. M. (2006). How dual are dual-income couples? documenting change from 1970 to 2001. J. Marriage Fam. 68, 11-28. doi: 10.1111/j.17413737.2006.00230.x

[31]. Ringera, K. (2017). racking the political leadership ceiling in Kenya: The 2017 general election and women. McCain Institute Arizona State University.

[32]. Schoon, I., \&. Parsons, S. (2002). Teenage aspirations for future careers and occupational outcomes. J. Vocat. Behav. 60, 262-288. doi: 10.1006/JVBE.2001.1867

[33]. Sifuna, D. N. (2006). A review of major obstacles to women's participation in higher education in Kenya. Research in Post-Compulsory Education, 11(1), 85105. https://tandfonline.com 


\section{Yinternational Research Journal}

p-ISSN 2202-2821 e-ISSN 1839-6518 (Australian ISSN Agency)

[34]. Webb, R. M., Lubinski, D., \&. Benbow, C. P. (2002). Mathematically facile adolescents with math-science aspirations: new perspectives on their educational
Vol. 11 No. 022021

828011022021173 (c) Author(s)

and vocational development. J. Educ. Psychol. 94, 785-794. doi: 10.1037/0022-0663.94.4.785

[35]. Williams, J. E. (1990). Measuring Sex Stereotypes: A Multination Study. Sage. 


\section{Manuscript Processing Footprints}

\section{A. Journal Volume/Issue Details}

This manuscript it published in Vol. 11 No. 022021 issue of IARS' International Research Journal (I'IRJ).

This is a Peer Reviewed (Refereed) International Journal published by IARS' Press Australia (International Association of Research Scholars) The Volume/Issue is a regular issue of the journal published in August 2021 Available at: https://researth.iars.info/index.php/curie.

\section{B. Copyright, License, and Publishing Rights}

- IARS' Press Australia (International Association of Research Scholars) respects the rights of the authors of research content published with IARS' International Research Journal. The "First Publication Rights" (FPR) to the original work accepted for publication at IARS' International Research Journal is granted to the Publisher of the Journal but copyright for all work published in the journal is retained by the author(s). Works published in the Journal is distributed under a Creative Commons Attribution 4.0 International License (CC B Y 4.0). (This license lets others distribute, remix, adapt, and build upon your work, even commercially, as long as they credit you for the original creation. This is the most accommodating of licenses offered. Recommended for maximum dissemination and use of licensed materials.)

- After publishing the content with IARS' International Research Journal, the author holds complete right on the content for its amendments and reuse in any form. IARS' International Research Journal confirms that author(s) holds the copyright of the content.

- $\quad$ Author(s) grant(s) permission for their work to be indexed in part/full form in commercial and non-commercial indexes. Author(s) grant(s) permission for their work to be harvested in part/full form in commercial and non-commercial archives and distributed through them. Author(s) grant(s) permission for their work to be translated in part/full form in any language and republished and redistributed. Author(s) may enter into separate, additional contractual agreements for the non-exclusive distribution of the published version of the work, with an acknowledgement of its initial publication in this Journal.

- It is the responsibility of the author(s) to secure all necessary copyright and/or permissions for the use of third-party content in their manuscript(s). Author(s) have declared the same at the time of submission of manuscript and 'may also be required' to provide written evidence of this permission anytime in case required for any purposes.

- Publications Ethics and other Terms and Conditions as mentioned on official website of IARS' International Research Journal.

\section{Last Plagiarism Report}

Settings: Similarity of 09 words in a row has been considered plagiarized.

Plagiarized (2\%)

Unique (98\%)

\begin{tabular}{|l|l|}
\hline Date & Aug 13, 2021. \\
\hline Words & 123 Words Plagiarized / Total Words 5314. \\
\hline Source & 7 Source(s) Identified. \\
\hline Remarks & Low similarity detected, check your supervisor if changes are required. \\
\hline
\end{tabular}

Exemption / Relaxation by Editor: None

\section{Processing Track}

\begin{tabular}{|l|l|}
\hline Date of Submission & 1 August 2021 \\
\hline Date of Final Review & 12 August 2021 \\
\hline Date of Acceptance \& Schedule & 15 August 2021 \\
\hline Date of Publishing & 29 August 2021 \\
\hline
\end{tabular}

